\title{
Access to Care
}

\section{Medigap Premiums and Medicare HMO Enrollment}

\author{
Catherine G. McLaughlin, Michael Chernew, \\ and Erin Fries Taylor
}

Objective. Markets for Medicare HMOs (health maintenance organizations) and supplemental Medicare coverage are often treated separately in existing literature. Yet because managed care plans and Medigap plans both cover services not covered by basic Medicare, these markets are clearly interrelated. We examine the extent to which Medigap premiums affect the likelihood of the elderly joining managed care plans.

Data Sources. The analysis is based on a sample of Medicare beneficiaries drawn from the 1996-1997 Community Tracking Study (CTS) Household Survey by the Center for Studying Health System Change. Respondents span 56 different CTS sites from 30 different states. Measures of premiums for privately-purchased Medigap policies were collected from a survey of large insurers serving this market. Data for individual, market, and HMO characteristics were collected from the CTS, InterStudy, and HCFA (Health Care Financing Administration).

Study Design. Our analysis uses a reduced-form logit model to estimate the probability of Medicare HMO participation as a function of Medigap premiums controlling for other market- and individual-level characteristics. The logit coefficients were then used to simulate changes in Medicare participation in response to changes in Medigap premiums.

Principal Findings. We found that Medigap premiums vary considerably among the geographic markets included in our sample. Measures of premiums from different insurers and for different types of Medigap policies were generally highly correlated across markets. Our models consistently indicate a strong positive relationship between Medigap premiums and HMO participation. This result is robust across several specifications. Simulations suggest that a one standard deviation increase in Medigap premiums would increase HMO participation by more than 8 percentage points.

Conclusions. This research provides strong evidence that Medigap premiums have a significant effect on seniors' participation in Medicare HMOs. Policy initiatives aimed at lowering Medigap premiums will likely discourage enrollment in Medicare HMOs, holding other factors constant. Although the Medigap premiums are just one factor affecting the future penetration rate of Medicare HMOs, they are an important driver of HMO enrollment and should be considered carefully when creating policy related to seniors' supplemental coverage. Similarly, our results imply that reforms to the Medicare HMO market would influence the demand for Medigap policies.

Key Words. Medigap, Medicare managed care, premium effect on enrollment decisions, HMOs, Medicare 
Policymakers and researchers have been interested for several decades in the insurance choices of Medicare beneficiaries. Of particular interest are the decisions to purchase supplemental insurance policies or to participate in Medicare managed care plans. The determinants and consequences of HMO (health maintenance organization) participation have attracted considerable attention in part because of the hope that Medicare HMOs will help contain cost growth in the Medicare program. Medicare HMOs also offer beneficiaries the option for an expanded set of benefits at a cost often below what they would otherwise have to pay.

Although access to expanded benefits is widely recognized as a primary motivation for joining Medicare managed care plans, there are other mechanisms by which Medicare beneficiaries might gain access to added benefits, specifically through supplemental coverage. ${ }^{1}$ Since the inception of Medicare in the 1960s, many elderly have purchased supplemental insurance policies to help cover gaps in the basic Medicare benefit package (Families USA 1996). ${ }^{2}$ Supplemental coverage can be obtained in one of two ways. Privately purchased supplemental policies, standardized by a 1990 federal law, are often referred to as "Medigap" policies and are available in 10 different benefit packages designated " $\mathrm{A}$ " through "J." retiree medical coverage is also available for some Medicare beneficiaries and is not subject to the restrictions on benefit design (Shea and Stewart 1995; Lillard, Rogowski, and Kington 1997).

Although the markets for Medicare HMOs and Medigap policies are interrelated, much research in this area has treated them as distinct. Studies that examine factors associated with the purchase of Medigap insurance typically do not recognize Medicare managed care as an alternative (e.g., Wolfe and Goddeeris 1991; Baker 1997; Ettner 1997; Vistnes and Banthin 1997). Similarly, studies that examine enrollment in Medicare managed care typically do not recognize the potential importance of factors related to the market for Medigap coverage (Cooper and Vladeck 2000; Swartz 1999; Newhouse 2000; Welch 1996, General Accounting Office report 1997a).

This work was supported by a grant from The Robert Wood Johnson Foundation's Changes in Health Care Financing and Organization initiative.

Address correspondence to Catherine G. McLaughlin, Ph.D., Professor, Department of Health Management \& Policy, M3166 SPH II, School of Public Health, The University of Michigan, Ann Arbor, MI 48109-2029. Michael Chernew, Ph.D., is an Associate Professor and Erin Fries Taylor, M.P.P., is a Research Assistant with the Department of Health Management \& Policy, School of Public Health, The University of Michigan. 
These studies tend to emphasize access to expanded benefits (particularly pharmaceuticals), federal HMO payment rates, and area characteristics such as density as the prime determinants of HMO enrollment.

The interrelationship between the markets is important because reforms in one market may influence enrollment in the other. Moreover, studies that do not recognize this interrelationship may inadvertently exclude relevant variables, creating an omitted variables bias. Our greatest concern in this regard is the estimates of the role that the adjusted average per capita cost (AAPCC) plays in influencing HMO enrollment. The AAPCC rates historically have been the basis of payments to HMOs. Typically a positive relationship between the AAPCC and HMO enrollment is taken as an indication of a supply effect. However, because both are related to local feefor-service (FFS) expenditure patterns, the price of Medigap coverage is likely correlated with the AAPCC. If the Medigap premiums are omitted, the AAPCC coefficient might be serving as a proxy for a cross-product demand effect as opposed to a supply effect. This relationship has implications for how one uses HMO payment rates to encourage HMO participation (Penrod, McBride, and Mueller 2001).

In this paper, we examine the extent to which Medicare beneficiaries in markets where Medigap coverage is relatively expensive are more likely to be enrolled in managed care plans. The analysis is based on a sample of Medicare beneficiaries drawn from the Community Tracking Study (CTS) Household Survey, which is merged with premium data that we collected from Medigap insurers. Using a reduced-form model, we find that the price of Medigap policies in a given market is positively related to $\mathrm{HMO}$ participation. This result is robust across several specifications. The result is not a precise measure of cross-price elasticity because we do not hold the price of HMO participation constant from an enrollee's perspective. However, it does indicate a strong positive relationship between the price of Medigap policies and participation in Medicare HMOs.

There are a few existing studies that also relate managed care enrollment to Medigap market traits. Specifically, Buchmueller (2000) examined how the premium for a Medicare supplemental policy affected HMO participation among Medicare-eligible retirees from the University of California. ${ }^{4}$ The study finds that the price of the Medicare supplemental policy is a significant factor in HMO participation, though not a large one. Our study addresses a similar issue in a national setting, where there are fewer restrictions (and subsidies) for available HMO options and less acceptance of managed care generally, compared to California. We also are able to incorporate better controls for individual health status. 
Rice et al. (2002) examine the impact of high premiums on whether Medigap policyholders switch to Medicare HMOs. Using data from the Medicare Current Beneficiary Survey, the authors find that higher Medigap premiums do not induce switching into managed care. Our model is not restricted to current Medigap policyholders and we use a market-level measure of the costliness of Medigap policies as opposed to a measure of the price of the chosen Medigap policy. Unlike Rice et al., we cannot address longitudinal issues related to enrollees switching plans.

\section{MODEL SPECIFICATION AND MeTHODS}

A Medicare beneficiary's participation in a Medicare $\mathrm{HMO}$ is a function of individual characteristics as well as market supply and demand factors. We estimate logit models of the following reduced form:

$$
\text { HMO Participation }_{\mathrm{ij}}=\alpha+\beta P_{j}+\phi X_{i}+\gamma M_{j}+\varepsilon_{i j}
$$

where:

HMO participation of individual $i$ is a binary indicator variable, where 1 indicates that the beneficiary is enrolled in an $\mathrm{HMO},{ }^{5}$

$P_{j}$ is an index of the price of Medigap coverage in market $j$,

$X_{i}$ is a set of demand characteristics of the individual (denoted by subscript $i$ ),

$M_{j}$ is a set of characteristics of the market (denoted by subscript $j$ ), and

$\varepsilon_{i j}$ is the error term.

The unit of analysis for this model is the individual Medicare beneficiary, though $P_{j}$ and $M_{j}$ reflect market characteristics. Individual characteristics included in the model $\left(X_{i}\right)$ represent determinants of the demand for Medigap. In general, because the market-level variables $\left(P_{j}\right.$ and $\left.M_{j}\right)$ measure availability of HMOs to the individual or attractiveness of the market to HMOs, we consider them supply characteristics. However, some market-level characteristics could proxy for demand traits. In our analysis, the standard errors are adjusted to account for the correlation that exists across individuals within a given market. Our base model and our sensitivity analyses are estimated using family-level weights that account for the sampling design of the CTS Household Survey (described below) and produce national estimates.

\section{Data SOURCES AND SAMPLE DEFINITION}

Table A-1 of the Appendix presents all variables included in this analysis and provides a detailed description, level of aggregation, and data source for each. 
Person-level characteristics, including HMO participation and person-level covariates, are taken from the CTS Household Survey, 1996-1997. The CTS includes individuals from 60 randomly selected sites nationwide. The 51 metropolitan sites were based on Metropolitan Statistical Areas (MSAs), while the 9 nonmetropolitan sites were based on Bureau of Economic Analysis' Economic Areas. ${ }^{6}$ Although CTS sites were intended to reflect local health care markets (Center for Studying Health System Change 1999), the boundaries of these sites may not always reflect insurers' or HMOs' perceptions of the market area. Nonetheless, given that the majority of the data used in this analysis come from the CTS (and therefore reflect its site boundaries), we use the CTS sites as indicative of health care markets.

Data on Medigap premiums come directly from a telephone survey of insurers that we conducted in the summer of 1999. Insurers typically did not have 1997 premium data available. The United Healthcare/AARP premiums used in this analysis pertain to 1998 policies and the Bankers Life premiums pertain to 1999 policies. To the extent that geographic variation in premiums is relatively stable over time, the lack of perfect correspondence between the year of enrollment and premium data will not bias the analysis substantially. The premium data should really be viewed as an index for 1997 premiums, as opposed to a direct measure of 1997 premiums.

Similarly, data on state regulatory characteristics are based on telephone conversations with state insurance departments in 1999. Respondents generally indicated that few changes occurred in relevant regulations between 1997 and 1999. Information on the 1997 AAPCC and on whether the site had a $\$ 0$ premium Medicare HMO in 1997 comes directly from the Health Care Financing Administration (2000a and 2000b, respectively). The HMO market penetration data for 1997 come from InterStudy (1997).

Medicare beneficiaries aged 65 or older are included in this analysis. Because the large majority of married seniors tend to make the same decision regarding $\mathrm{HMO}$ participation and insurance ${ }^{7}$, we view the decision to participate in an $\mathrm{HMO}$ as a family-level decision for the elderly. Therefore, we used only one respondent from each family, the person designated as the family informant for the CTS survey. (Note that the CTS selects the person in the family who is most knowledgeable about their family's health care decisions as the family informant.) Accordingly, we did not need to adjust for within-family correlation of coverage decisions.

Individuals in the CTS span 60 sites in 33 states across the United States. However, we excluded individuals in four CTS sites found in Massachusetts, Minnesota, and Wisconsin. These sites were not included because of state laws 
that preclude insurers from providing the standard Medigap policies A-J, prohibiting us from deriving a proper measure of the Medigap premium for these states. We also limited most of our analysis to only those sites in which Medicare HMOs exist. Twelve more CTS sites fell out of the analysis because of this exclusion criterion, leaving 44 CTS sites.

Table 1 presents the means of the variables included in our models of HMO participation. The means listed reflect all family informants in the 44 CTS sites in which Medicare HMOs exist $(n=3,385)$. Note that Bankers Life Plan C is available in only 40 of the 44 CTS sites and therefore has a smaller sample $(n=3,068)$.

\section{VARIABLE SPECIFICATION}

\section{Price of Medigap Coverage}

As stated above, the primary focus of our analysis is the relationship between the price of Medigap coverage and HMO enrollment. Measuring the price of Medigap coverage is complicated by the heterogeneity of available Medigap policies. There are three types of heterogeneity that could alter price, thus deserving attention.

First, there are 10 standardized benefit packages. The packages represent a range of benefits, with Plan A offering only basic benefits and Plan J offering the most comprehensive coverage. These policies are generally available in each market, though some policies are more common than others. ${ }^{8}$ Although Plan $\mathrm{F}$ is the most frequently purchased Medigap plan (Health Insurance Association of America 1998), premiums for Plan C are used in this analysis. Plan C, the second most popular Medigap plan, is offered in more states by more insurers than Plan $\mathrm{F}$ and therefore its use provides us with more data with which to identify HMO participation. For the models presented in this paper, we use the Plan C Medigap premiums of United Healthcare/AARP and Bankers Life. Although premiums from other insurers were collected, these two insurers cover the largest number of CTS sites.

Second, there are variations in terms of the pricing policy. For example, some states mandate that Medigap policies be community rated and others do not. We include a binary variable indicating whether a site is in a state that has mandatory community rating of Medigap policies. This variable may capture the attractiveness of the market to Medigap insurers, as well as the ability of beneficiaries to shop around for a low premium Medigap plan. Other plan distinctions that induce variation include whether the premium is based on the policyholder's attained (or current) age, on the age when the policy was 
Table 1: Means of Variables Included in Analysis, Unweighted-44 Sites*

\begin{tabular}{lcc}
\hline Variable & $\begin{array}{c}\text { Mean (or Percent, in } \\
\text { Case of Dummies) }\end{array}$ & $\begin{array}{c}\text { Standard } \\
\text { Deviation }\end{array}$ \\
\hline Medicare HMO participation & $20 \%$ & $40 \%$ \\
Male & $32 \%$ & $47 \%$ \\
Physical health (SF-12) & 43.5 & 11.8 \\
Mental health (SF-12) & 54.1 & 9.3 \\
Public coverage & $8 \%$ & $27 \%$ \\
Age & 74.0 & 6.57 \\
Married & $40 \%$ & $49 \%$ \\
Income & $\$ 32,520$ & $\$ 29,350$ \\
White & $78 \%$ & $41 \%$ \\
Large urban area (>200 K) & $94 \%$ & $23 \%$ \\
Premium for AARP Plan C & $\$ 1,379$ & $\$ 291$ \\
Premium for Bankers Life Plan C & $\$ 1,312$ & $\$ 236$ \\
Medicare HMO with \$0 premium exists & $76 \%$ & $43 \%$ \\
Overall managed care penetration & $30 \%$ & $13 \%$ \\
Community rating required by state law & $23 \%$ & $42 \%$ \\
AAPCC (for Parts A and B combined) & $\$ 496$ & $\$ 92$ \\
\hline
\end{tabular}

* Only individuals in the 44 sites in which Medicare HMOs exist are included in the calculations for this table. The sample for the mean Bankers Life Plan C is $n=3,068$; for all other variables, $n=3,385$.

first issued, or if the premium is not age-rated (i.e., community rating is used even when not if the premium mandated by state law). Insurers typically use the same pricing scheme for all areas, though there is some variation as a result of state regulatory rules. ${ }^{9}$ Our results were not sensitive to specifications that included binary variables to capture variations in pricing schemes (e.g., age at issue rating).

Third, even for standardized policies in the same market with identical observable characteristics, there is substantial variation in premiums across insurers. ${ }^{10}$ This variation may reflect some variation in plan quality, but is also likely to reflect a lack of competition attributable to imperfect information (and thus lack of search) among the elderly. The choice of Medigap policy is endogenous. In a complete demand system, all products and all prices would be included. However, estimation of a complete demand system, including HMO options, is not feasible given our limited, survey-based data. In our models, we consider one plan, from a single insurer, as representative of a standard product and use premiums for that policy to represent a price index.

In our base model, we use the United Healthcare/AARP Plan C policy as the standard and then test the sensitivity of our results using Bankers Life Plan C. Our data reveal that Medigap premiums tend to move together across sites. Table 2 reports the correlation in premiums for Plans $\mathrm{C}$ and $\mathrm{F}$, the two most popular plans, for United Healthcare/AARP and Bankers Life. There 
Table 2: Correlations in Premiums for Plans C and F-44 Sites

\begin{tabular}{lccccc}
\hline & & AARP & AARP & Bankers & Bankers \\
\hline Insurer & Plan & $C$ & $F$ & $C$ & $\mathrm{~F}$ \\
AARP & $\mathrm{C}$ & 1 & 0.942 & 0.657 & 0.396 \\
AARP & $\mathrm{F}$ & & 1 & 0.673 & 0.486 \\
Bankers & $\mathrm{C}$ & & & 1 & 0.836 \\
Bankers & $\mathrm{F}$ & & & & 1 \\
\hline
\end{tabular}

are generally strong correlations across plans $\mathrm{C}$ and $\mathrm{F}$ for a given insurer. ${ }^{11}$ Therefore, either plan type should do reasonably well as a representative price index for a Medigap policy and the results of our model should not be particularly sensitive to our choice of Plan C. Furthermore, correlations across the two different insurers are also fairly strong. Therefore, even though plan premiums may differ significantly across insurers within a given site, they are likely to move together across CTS sites. Our analysis measures how the likelihood of HMO participation among Medicare beneficiaries varies with an index of the costliness of Medigap policies in their market. We consider the specific Medigap policy that they purchase (if any), and its premium, to be endogenous.

\section{Individual Characteristics}

The model also includes attributes of the beneficiaries because these attributes largely determine the demand for Medicare HMOs. We include the respondent's physical and mental health scores from the SF-12 survey, ${ }^{12}$ as well as the respondent's age, which will be correlated with health status. Age of the respondent may also serve as a proxy for their familiarity with HMOs as younger beneficiaries are more likely to have been enrolled in an HMO prior to Medicare eligibility. We also include gender, income, race, and marital status. Additionally, we add a measure of whether the individual is enrolled in Medicaid or another public health program, which captures both additional sociodemographic information and eligibility for alternative insurance options.

\section{Market Characteristics}

Medicare HMOs. In a full demand system, we would also include information regarding available HMOs and their associated premiums. Like measurement of Medigap premiums, measurement of HMO premiums is complicated by heterogeneity in available products. ${ }^{13}$ To complicate matters further, the premium received by the $\mathrm{HMO}$ is not the same as that paid by the beneficiary. During our study period, the Health Care Financing Administration (HCFA) 
paid HMOs according to a formula based on the AAPCC for FFS Medicare enrollees in the beneficiary's county. Moreover, if the premium exceeds costs by a sufficient amount, HMOs were required to add benefits, though accounting practices may render this restriction relatively insignificant. The HMOs in general offer additional benefits, perhaps because of this restriction or perhaps as a way to attract enrollees. Some HMOs charge an additional premium over and above the beneficiary's Part B premium in exchange, presumably, because they offer a more desirable benefit package.

As with the selection of Medigap policies, the specific choice of HMO is endogenous. Our model includes a measure of the AAPCC (Parts A and B combined), which largely captures the amount that HMOs are paid to participate in the market. Actual payments to HMOs are adjusted for beneficiary age and gender. Whether higher AAPCC payments are sufficient to attract HMOs into a market depends on whether the higher payment offsets the higher cost upon which the AAPCC was based. It is likely that HMOs find high AAPCC markets attractive because those markets may have higher utilization levels or higher prices, which the HMO could control and thereby achieve some profit, provided the rate of return restriction can be avoided through accounting practices. ${ }^{14}$

The overall penetration of HMOs in the market was included to capture potential economies of scope between commercial and Medicare beneficiaries. For some large nonmetropolitan CTS sites, the state's average HMO penetration was used since HMO penetration for the defined site (e.g, northern Georgia) was not available. Presumably it is cheaper at the margin to serve Medicare beneficiaries if a large commercial network has been established. Therefore HMOs should be more willing to serve Medicare beneficiaries if they already have a large commercial population. This variable also captures the general attractiveness of the market to HMOs, beyond that captured by the AAPCC, and perhaps community acceptance of managed care. We also include an indicator for large urban areas, that is, whether the CTS site has more than 200,000 residents. Other studies have suggested that larger, more densely populated markets are more attractive to managed care plans (United States General Accounting Office 1997a).

In one of our sensitivity analyses, we include an indicator for whether there exists a $\$ 0$ premium Medicare HMO in the site (that is, a Medicare HMO that charges nothing over the beneficiary's Part B premium). Depending on benefit design, these low priced HMOs may induce more participation.

Employer Coverage. The model specified suffers from one major omission. We do not have sufficient information on availability of supplemental 
coverage through employers. The CTS asks respondents whether they have employer-sponsored supplemental coverage or employer-sponsored HMO coverage. Although this information tells us who has this type of coverage through their (former) employer, it does not reveal which individuals had the choice of coverage through their employer. Without information on who had what options, we cannot estimate a more structural model of benefit decisions. As Lillard, Rogowski, and Kington (1997) note, the availability of employersponsored retiree health insurance coverage is an important determinant of whether an individual actually has supplemental coverage. It affects both HMO availability and the cost of supplemental coverage. Therefore, the coefficients in our base model must be interpreted as measuring the average impact of the cost of Medigap policies in a given market. To some extent this will be correlated with the cost of employer-sponsored coverage options (and maybe even their availability), but because individuals can move after retirement and employer benefit packages for retirees may have been designed well in the past, we are not sure of the extent of this correlation.

In addition, all of the coefficients on beneficiary characteristics must be interpreted with the understanding that their impact may work through their correlation with the likelihood of employer-sponsored coverage. For example, a negative coefficient on income may indicate that low-income individuals have a greater acceptance of HMOs or it may indicate they have reduced access to employer-subsidized supplemental coverage. Similarly, markets with high Medigap premiums may encourage HMO enrollment because beneficiaries are more likely to choose HMOs relative to Medigap coverage or because employers in these markets are less likely to subsidize supplemental coverage, driving beneficiaries to purchase their own HMO coverage. ${ }^{15}$ We would expect less sensitivity to Medigap premiums in our model, relative to one in which we could measure the sensitivity of beneficiaries who do not have employer-subsidized coverage.

\section{RESULTS AND INTERPRETATION}

Table 3 presents our logit models estimating Medicare HMO participation. Model 1 in Table 3 is our base model, using the log of United Healthcare's AARP Medigap premium for Plan $\mathrm{C}$ in each CTS market. The Medigap premium is strongly and positively predictive of participation in a Medicare $\mathrm{HMO}$, and the coefficient on the Medigap premium remains stable through subsequent models. The Medigap premium has a much larger effect on Medicare HMO participation than any other variable in the model. Areas of 
high overall HMO penetration also are associated with higher Medicare HMO participation. The average AAPCC for the CTS site is not predictive of HMO participation. Controlling for various demographic characteristics, good physical health and being male are associated with HMO participation, while age is inversely related to participation. Other variables have the expected signs or are insignificant predictors. ${ }^{16,17}$

United Healthcare uses community rating to price its AARP-sponsored Medigap plans, charging the same rate to all seniors in a given market, regardless of age. As such, United Healthcare policies may be less attractive to younger Medicare beneficiaries who may be offered lower Medigap prices through other insurers. In Model 2 we use Bankers Life Plan C premium to check for how sensitive the results are to AARP's pricing scheme. ${ }^{18}$ In general, the results are robust. The Bankers Life Plan C premium is also positively related to HMO participation, and strongly significant. The effect of the Medigap premium in Model 2 leads to similar conclusions as Model 1. Residing in a large urban area now leads to a statistically significant higher probability of enrolling in a Medicare HMO. ${ }^{19}$

As discussed above, we have little data on how HMOs vary across CTS sites. Such differences in HMOs certainly could affect participation. We therefore estimate a model that includes an available, albeit rough, indicator that could affect HMO participation. Specifically, Model 3 in Table 3 adds a binary variable indicating whether each market has a Medicare $\mathrm{HMO}$ with a $\$ 0$ premium. ${ }^{20} \mathrm{In}$ this model, the Medigap premium remains a strong and significant predictor of HMO participation. As expected, the existence of a $\$ 0$ premium HMO is positively related to participation, though it is not significant at the $10 \%$ level.

Overall HMO penetration includes those individuals participating in Medicare HMOs. Because overall penetration and Medicare penetration generally move in the same direction, overall $\mathrm{HMO}$ penetration is somewhat endogenous to our model. We therefore ran Model 4, which includes commercial HMO penetration instead of overall HMO penetration. Commercial HMO penetration reflects enrollment in commercial HMOs only, that is, it does not include enrollment in Medicare or Medicaid HMOs. Because we have commercial penetration data for only large urban sites (InterStudy 1997), three CTS sites that are not large urban areas are excluded from this model and the indicator for large urban areas is not included. The Medigap price is still strongly predictive of $\mathrm{HMO}$ participation. The coefficient on commercial HMO is statistically significant ( $p=10$ percent) in this model.

Model 5 in Table 3 presents the base model again, but with all 56 of the CTS sites (excluding those four CTS sites in Massachusetts, Minnesota, and 


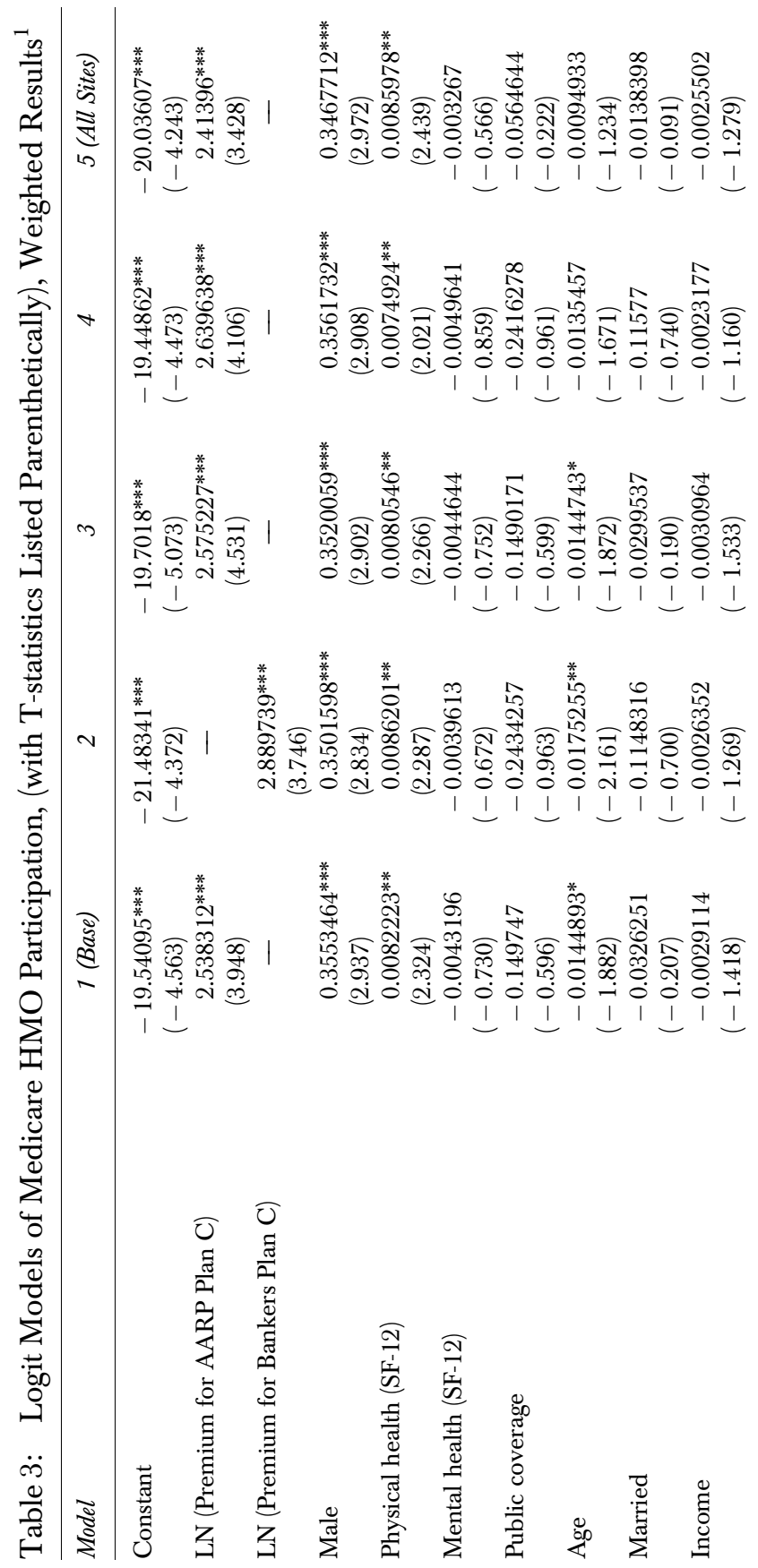




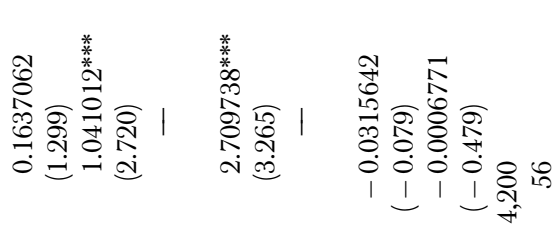

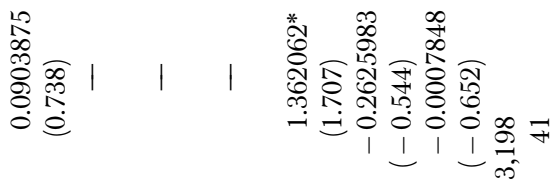

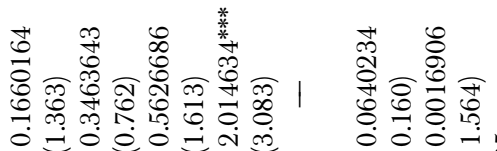

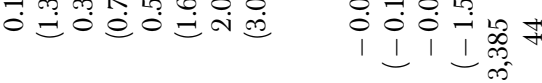

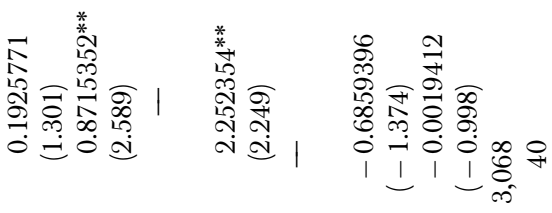

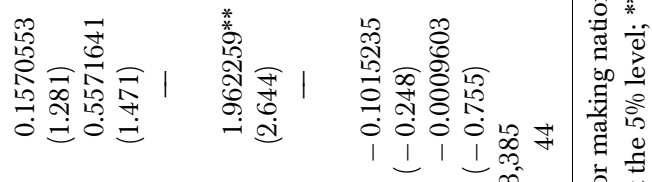

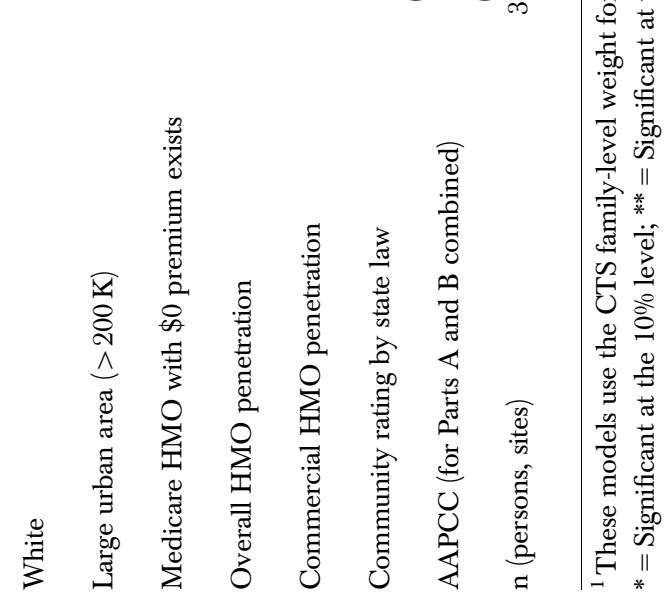


Wisconsin). Inclusion of all sites is appropriate if the main mechanism by which low Medigap premiums discourage HMO enrollment is through discouraging HMO entry in the Medicare market. As discussed above, 12 of these 56 sites have no Medicare HMOs available. ${ }^{21}$ The estimated impact of Medigap premiums on HMO participation remains consistent with the results from the base model, though it should be noted that the Medigap price's coefficient in this case is the direct effect of the Medigap price on enrollment, as well its effect through HMO entry.

In addition to the models presented in Table 3, we conducted other sensitivity analyses. For example, we altered the base model (Model 1) by substituting the large urban area dummy variable with the site's population density. In another model, we included measures of hospital and physician market structure, such as the total number of hospitals, hospital beds per capita, and doctors per capita, which could relate to HMO costs as well as Medigap costs. We also ran models using Bankers Life Plan F and AARP Plan $\mathrm{F}$ as the Medigap premium. In all of these sensitivity analyses, the coefficient on the Medigap premium remained positive and statistically significant. We also ran unweighted versions of the models presented in Table 3 and found similar results to our weighted models.

To assess the magnitude of the impact of Medigap prices on HMO participation, we computed the predicted probabilities of participating in a Medicare HMO for three of our models (Table 4). We calculated these probabilities based on the complete sample of respondents for each of the models. The average participation rate of individuals across CTS sites is

Table 4: Probability of Participating in a Medicare HMO, for Various Simulations*

\begin{tabular}{lccc}
\hline Simulation & $\begin{array}{c}\text { Model 1 } \\
(n=3,385)\end{array}$ & $\begin{array}{c}\text { Model 2 } \\
(n=3,068)\end{array}$ & $\begin{array}{c}\text { Model 3 } \\
(n=3,385)\end{array}$ \\
\hline Mean AARP Plan C premium & $19.9 \%$ & - & $20.1 \%$ \\
$\begin{array}{l}\text { Mean AARP Plan C premium } \\
\text { plus 1 standard deviation }\end{array}$ & $28.5 \%$ & - & $28.9 \%$ \\
$\begin{array}{l}\text { Mean Bankers Plan C premium } \\
\begin{array}{l}\text { Mean Bankers Plan C premium } \\
\text { plus 1 standard deviation }\end{array}\end{array}$ & - & $21.7 \%$ & - \\
$\begin{array}{l}\text { Implied Arc Elasticity** } \\
\text { mor }\end{array}$ & 2.05 & $30.5 \%$ & - \\
\hline
\end{tabular}

* Based on the entire sample of respondents used in each of the models.

** Calculated as the percentage change in HMO participation over the percentage change in Medigap premium.

Note: The mean AARP Plan C premium is $\$ 1,379$, with a standard deviation of $\$ 291$. The mean Bankers Plan C premium is $\$ 1,312$, with a standard deviation of $\$ 236$. 
around 21 percent. $^{22}$ The first row of Table 4 shows the estimated rate of HMO participation when each site is assigned the mean United Healthcare/ AARP Plan $\mathrm{C}$ premium. In the next row of the table, we increased this mean premium by one standard deviation and estimated the new rate of HMO participation. We also present estimates using the Bankers Life Plan C premium. Given our results, if Medigap prices continue to increase as they have in recent years, we would expect Medicare HMO penetration to increase as well. The simulations suggest that a one standard deviation increase in Medigap prices (based on individual responsiveness to the AARP Plan C coefficient) would increase HMO participation by more than 8 percentage points, to almost 29 percent. In contrast, a one standard deviation increase in physical health status would be predicted to increase enrollment by only 1.5 percentage points, suggesting that Medigap premiums are indeed an important predictor of enrollment.

\section{DISCUSSION}

The results of this analysis are robust across several specifications, using weighted and unweighted approaches. In all models presented in this paper, as well as other model specifications not presented, the Medigap premium, the key independent variable of interest for this analysis, is always a positive and statistically significant predictor of Medicare HMO participation. Clearly, Medicare beneficiaries view Medigap policies and Medicare HMOs as substitutes.

These results have several policy implications. First, and perhaps most importantly, policies aimed at lowering (or at least stabilizing) Medigap prices will discourage HMO participation, holding other factors constant. Despite standardized Medigap benefits, Medigap prices vary widely. We would expect efforts to control this price variability to have ramifications in the HMO market. Second, although evidence for adverse selection in the Medigap market is mixed (Wolfe and Goddeeris 1991; Browne and Doerpinghaus 1995; Ettner 1997), adverse selection could play more of a role in the Medigap market in the future. If strong adverse selection occurs, prices for Medigap policies will increase, resulting in growth in $\mathrm{HMO}$ participation. Although the Medigap price is just one factor affecting the future growth of Medicare HMO enrollment, it is nonetheless an important driver and one that should be considered when creating policy related to Medicare beneficiaries' supplemental coverage. 
There are several limitations to this analysis that warrant discussion. One of the most important concerns involves the issue of endogeneity, which may be particularly salient because of our cross-sectional research design. Although we have modeled HMO participation as a function of Medigap prices, favorable selection into Medicare HMOs could affect Medigap premiums in the market. Therefore, it is possible that we are observing correlation between Medigap prices and HMO participation, rather than causation. However, our analysis examines an individual's decision to participate in Medicare HMOs. At any point in time, an individual observes Medigap prices in the market and chooses whether to join a Medicare HMO. Individual beneficiaries cannot influence the Medigap premium in the market and therefore we assume that the Medigap premium is exogenous to the individual.

Endogeneity may still be a concern if there are unobserved market-level factors correlated with both the error term and Medicare HMO participation. For example, if a particular market has higher-quality HMOs relative to other markets, this characteristic will increase participation in Medicare HMOs. If this increased enrollment is systematical among relatively healthy beneficiaries, Medigap premiums may also rise. In this case we would expect the coefficient on the Medigap premium to be sensitive to the inclusion of marketlevel variables and those measuring HMO traits. Yet, we find that the Medigap coefficient is not very sensitive to the inclusion of several market factors, such as the number of hospital beds per capita and the presence of a $\$ 0$ premium Medicare HMO. Although we cannot dismiss the possibility of endogeneity, our sensitivity analyses show robust Medigap coefficients in a number of different specifications that include market-level factors.

Another limitation involves the fact that some important variables are omitted from the model due to the lack of available data. Characteristics of HMOs, such as the level of benefits provided, the premiums charged by HMO plans, and the amount of cost sharing, are not available from the CTS. Similarly, adequate data on an individual's employer-sponsored retiree coverage are not available. We would hope to incorporate at least some market-level measures of average retiree coverage in future analyses of HMO participation. The level of supplemental retiree coverage is important because one would expect it to be inversely related to HMO participation (United States General Accounting Office 1997a). Finally, income is the only measure of wealth available from the CTS, but is not a complete measure of ability to pay, particularly among the elderly. Given that past analyses (Ettner 1997; Wolfe and Goddeeris 1991) have found wealth to be a strong predictor of 
Medigap purchase, it is likely that wealth plays a significant role in Medicare HMO participation. A good measure of wealth such as net worth would likely show a strong and significant negative influence on participation. It is not clear if any of these omitted variables would affect the coefficient on Medigap price, which was stable across numerous specifications.

Another possible limitation involves the fact that we use family informants from the CTS as the sample in our models of HMO participation. We view the decision regarding $\mathrm{HMO}$ participation as a family-level decision, and therefore model only the behavior of the family informant. However, if the relationship between the covariates and the decision regarding HMO participation differed for the family informant relative to other family members, the choice of the family informant could bias the model coefficients. We consider this possibility unlikely. Reestimating our base model including all family members yields similar results to those presented here.

Finally, measurement error is another concern with several of the variables presented in this analysis. For example, the Medigap premium data from United Healthcare/AARP and Bankers Life reflect 1998 and 1999 prices, rather than 1997 prices (the year of the CTS survey). Furthermore, choosing a single insurer's Medigap price for Plan $\mathrm{C}$ in the market is not a perfect representation of that market's Medigap prices. Additionally, there is inevitably some measurement error in data taken from any survey. When asked about their health insurance in the course of a survey, many individuals may not be able to identify accurately whether they are enrolled in an HMO (Dranove, Simon, and White 1998). Such data issues are common in this type of work and we believe the survey data and premium data are among the best available. Further study would be needed to assess how these issues affect our findings.

\section{CONCLUSIONS}

This research provides clear evidence that Medigap premiums have a significant effect on an individual beneficiary's decision to participate in a Medicare HMO. Future research aimed at determining the relationship between Medicare FFS, Medigap, and Medicare managed care could help predict how these markets might change and grow in the next few years, particularly in the era of Medicare+Choice. Furthermore, careful analysis of these markets can reveal how both individuals and markets shape health care choices and perhaps even shed light on how reforms to either market may influence Medicare beneficiaries' decisions. 


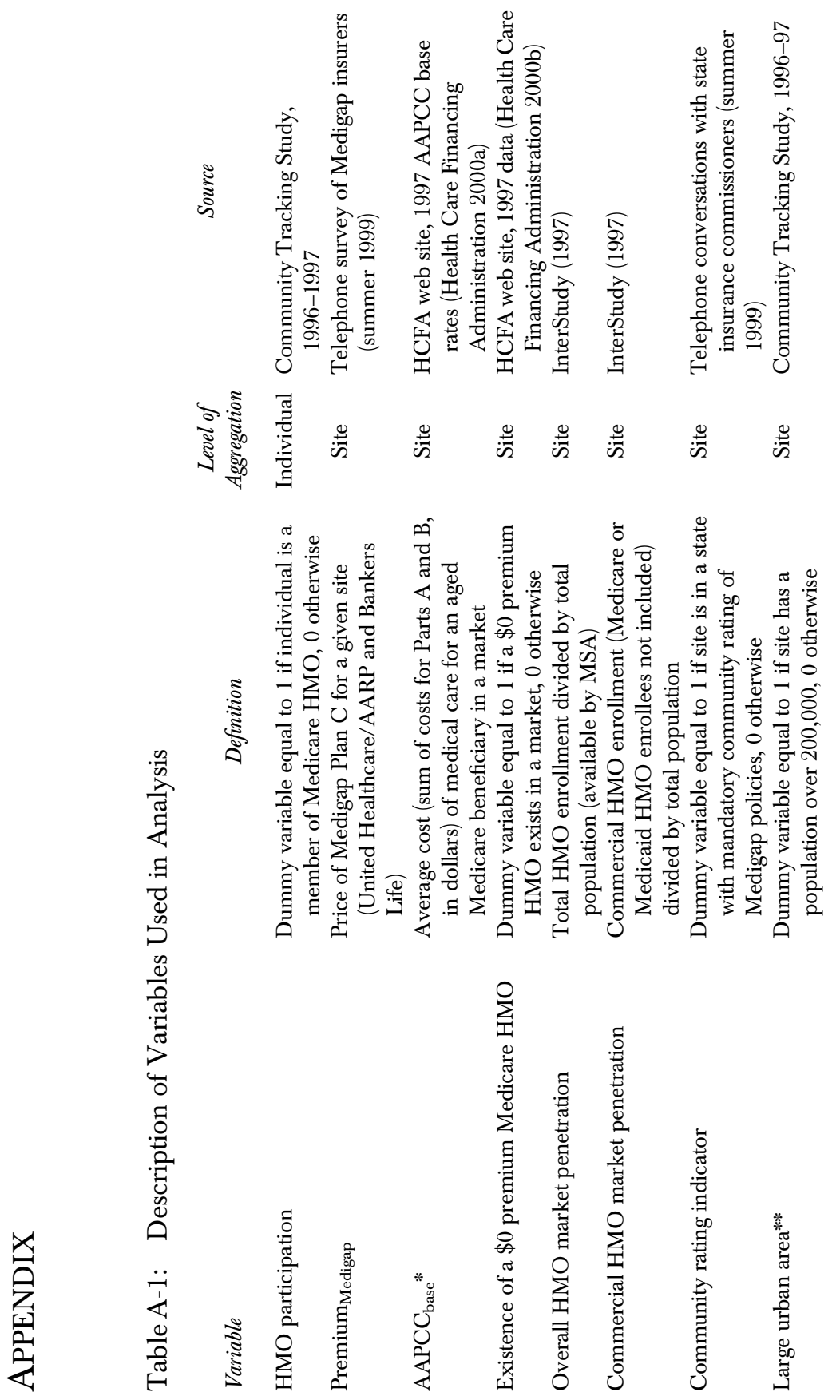




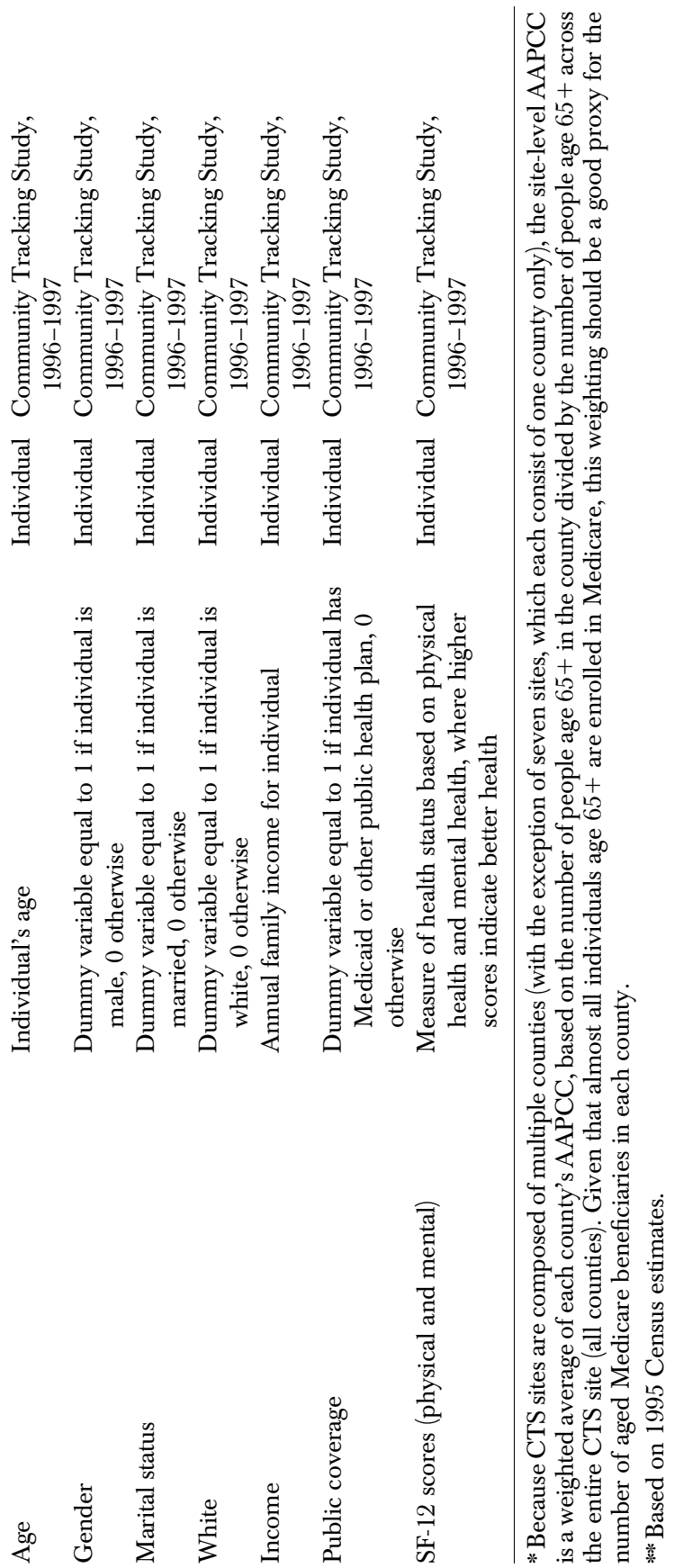




\section{NOTES}

1. Some researchers refer to any coverage beyond traditional Medicare fee-for-service coverage (Parts A and B) as supplemental, including Medicare HMO and Medicaid coverage. However, for the purposes of this paper, we define supplemental coverage as either privately purchased Medigap or employersponsored Medicare supplemental coverage.

2. Even with supplemental or HMO coverage, the elderly still face substantial out-ofpocket health costs (see Crystal et al. 2000).

3. Plan A is the basic benefits plan, covering the coinsurance for services received under Medicare Part A (hospitalization) and Part B (outpatient and physician services). Plans B through J offer increasing levels of benefits above the basic benefits package. For example, Plan $\mathrm{C}$ covers coinsurance for Medicare Parts A and B, the deductibles for inpatient as well as outpatient and physician services, coinsurance for a skilled-nursing facility, and foreign travel emergency. Only plans H, I, and J offer any prescription drug coverage, with $\mathrm{J}$ offering the most extensive coverage $(\$ 3,000$ maximum for prescription drugs per year).

4. Although Buchmueller (2000) refers to this employer-sponsored supplemental coverage as Medigap, we use the term "Medicare supplemental policy" to distinguish it from privately-purchased Medigap.

5. The Medicare beneficiary may be enrolled in an HMO through private purchase of a policy or through an employer or union. We are not able to make fine distinctions between various types of HMOs (e.g., staff model HMOs, IPA models, etc.) because this information is not available from the CTS.

6. Nonmetropolitan sites included in the CTS are composed of large numbers of counties and often represent substantial portions of a state, such as "Central Arkansas" or "Eastern Maine."

7. Of those married seniors in two-person families in which both individuals are aged $65+$, more than 96 percent of individuals have the same HMO coverage status as their spouse. Furthermore, of those married seniors in two-person families in which both individuals are aged $65+$, more than 91 percent of individuals have the same type of insurance as their spouse (defined as Medicare only; Medicare and private coverage; or Medicare and public coverage).

8. All insurers who sell Medigap are required to offer Plan A by federal law but may choose what other Medigap Plans B-J they will offer in the market.

9. United Healthcare/AARP uses community rating in 53 of the 56 sites (using age at issue only in the three Florida sites). Bankers uses attained age rating in all but 6 of the 52 CTS sites in which it sells insurance.

10. A press release from Weiss Ratings, Inc. (2000) stated that Medigap premiums vary widely not only from state to state and city to city, but insurer to insurer. Within the same market, Weiss Ratings found that some insurers charged twice as much as other insurers for the same Medigap plan. Our telephone survey of insurers revealed similar results. Within a given market, premiums for the same Medigap 
plan ranged as much as $\$ 800$ between the lowest and highest priced insurers. The highest priced insurers charge up to 1.7 times the lowest priced insurers.

11. Bankers Life Plan F is not very highly correlated with the AARP plan premiums. Therefore, we conducted a sensitivity analysis using this plan as the Medigap premium. The conclusions are even stronger with this measure of Medigap premiums, with the estimated coefficient rising about 50 percent. However, use of Bankers $\mathrm{F}$ premium limits our sample because it is not offered in all markets and there appears to be substantial correlation between the Bankers $\mathrm{F}$ premium and several other market-level variables (large urban site, state community rating, and HMO penetration). Thus we believe the reported results are preferable.

12. The SF-12 is a series of 12 questions used to rate respondents' health on a one hundred point scale, where higher scores indicate better health status. The SF-12 questions for both physical and mental health were asked of CTS respondents.

13. Indeed, there is quite a bit more heterogeneity in Medicare HMO products relative to Medigap policies because Medicare HMO benefits have not been standardized.

14. Pai and Clement (1999) found that the AAPCC is a positive and significant predictor of Medicare HMO entry into a market.

15. One could estimate a model using market-level proxies for employer-subsidized coverage (such as the percentage of employment in manufacturing and the percentage of large firms), but these proxies would be imperfect because Medicare beneficiaries may reside in markets other than those in which they were employed.

16. We considered using the person-specific AAPCC, adjusted for individual factors like age, gender, and Medicaid status. However, because the person-specific AAPCC was highly correlated with other independent variables, we did not include it in the final models.

17. As discussed earlier, we view the decision to participate in an HMO as a familylevel decision for the elderly and therefore include only the family informant in our models. Nonetheless, we also estimated the base model using the sample of all family members. This analysis yielded very similar results to those reported, except the coefficient on income is statistically significant.

18. Unlike United Healthcare/AARP, Bankers Life prices its premiums based on age (specifically, by attained age, except where prohibited by state law) and zip code. For our analysis, we use the Bankers Life premium for a 65-year-old who enrolls during the open enrollment period.

19. Relative to the base model (Model 1), Model 2 includes four fewer sites. The four sites, all of which are large urban areas, were not included because Bankers Life does not offer Medigap policies in these areas.

20. According to the Health Insurance Institute of America (1998), about 57 percent of Medicare managed care plans did not have a premium beyond the regular Medicare Part B premium. Other sources estimate that two-thirds of plans have no premiums (Health Care Financing Administration 2000b; personal communication with Beth Kosiak, HCFA, June 7, 1999).

21. There are a few respondents (fewer than 3 percent) who stated that they belonged to a Medicare HMO despite the fact that InterStudy data indicated no Medicare 
HMOs in their area. Of course, this could be explained in several ways. Specifically, individuals may choose to travel some distance to HMO providers. Alternatively, some respondents could be misinformed about whether they are enrolled in an HMO.

22. Medicare HMO participation in any CTS site ranged from 0 percent to almost 54 percent.

\section{REFERENCES}

Baker, L. 1997. "The Effect of HMOs on Fee-for-Service Health Care Expenditures: Evidence from Medicare." Journal of Health Economics 16 (4): 453-81.

Browne, M. J., and H. Doerpinghaus. 1995. "Asymmetric Information and the Demand for Medigap Insurance.” Inquiry 31 (4): 445-50.

Buchmueller, T. C. 2000. "The Health Plan Choices of Retirees Under Managed Competition." Health Services Research 35 (5, part 1): 949-76.

. 1999. Community Tracking Study Household Survey, 1996-1997: Codebook for Site and County Crosswalk Data File. ICPSR study no. 2524. Washington, DC: Center for Studying Health System Change (producer), Inter-University Consortium for Political and Social Research (distributor).

- 1998a. Community Tracking Study Household Survey, 1996-1997: Codebook. ICPSR study no. 2524. Washington, DC: Center for Studying Health System Change (producer), Inter-University Consortium for Political and Social Research (distributor).

Center for Studying Health System Change. 1998b. Community Tracking Study Household Survey, 1996-1997: User Guide. ICPSR study no. 2524. Washington, DC: Center for Studying Health System Change (producer), Inter-University Consortium for Political and Social Research (distributor).

Christensen, S., and J. Shinogle. 1997. "Effects of Supplemental Coverage on Use of Services by Medicare Enrollees." Health Care Financing Review 19 (1): 5-17.

Cooper, B. S., and B. C. Vladeck. 2000. "Bringing Competitive Pricing to Medicare." Health Affairs 19 (5): 49-54.

Cox, D. F., and C. Hogan. 1997. "Biased Selection and Medicare HMOs: Analysis of the 1989-1994 Experience." Medical Care Research and Review 54 (3): 259-74.

Crystal, S., R. W. Johnson, J. Harman, U. Sambamoorthi, and R. Kumar. 2000. "Outof-Pocket Health Care Costs Among Older Americans.” Journal of Gerontology: Social Sciences 55B (1): S51-62.

Dranove, D., C. J. Simon, and W. D. White. 1998. "Determinants of Managed Care Penetration." Journal of Health Economics 17 (6): 729-45.

Ettner, S. L. 1997. "Adverse Selection and the Purchase of Medigap Insurance by the Elderly." Journal of Health Economics 16 (5): 543-62.

Families USA. 1996. “The Crushing Costs of Medicare Supplemental Policies.” Special Report. October.

Fox, P. D., R. Snyder, G. Dallek, and T. Rice. 1999. "Should Medicare HMO Benefits Be Standardized?" Health Affairs 18 (4): 40-52. 
Health Care Financing Administration. 1996. Profiles of Medicare: 30th Anniversary. Baltmore, MD: Health Care Financing Administration.

. 2000a. "Historical AAPCC and Medicare+Choice Payment Rates [accessed on November 9, 2000]." Available at: http://www.hcfa.gov/stats/hmorates/ aapccflt.htm.

- 2000b. "Monthly Report-Medicare Coordinated Care Health Plans [accessed on November 9, 2000]." Available at: http://www.hcfa.gov/stats/monthly.htm.

Health Insurance Association of America. 1998. Source Book of Health Insurance Data, 1997-1998. Washington, DC: Health Insurance Association of America.

Hellinger, F. J. 1995. "Selection Bias in HMOs and PPOs: A Review of the Evidence." Inquiry 32 (2): 135-42.

InterStudy. 1997. Competitive Edge (release 7.2) statistical software, Part III: Regional Market Analysis. St. Paul, MN: InterStudy Publications.

Lichtenstein, R., J. W. Thomas, J. Adams-Watson, J. Lepkowski, and B. Simone. 1991. "Selection Bias in TEFRA-at-risk HMOs." Medical Care 29 (4): 318-31.

Lillard, L., J. Rogowski, and R. Kington. 1997. "Long-Term Determinants of Patterns of Health Insurance Coverage in the Medicare Population." Gerontologist 37 (3): 314-23.

Newhouse, J. P. 2000. "Switching Health Plans to Obtain Drug Coverage." Journal of the American Medical Association 283 (16): 2161-2.

Pai, C.-W., and D. G. Clement. 1999. "Recent Determinants of New Entry of HMOs into a Medicare Risk Contract: A Diversification Strategy.” Inquiry 36 (1): 78-89.

Penrod, J. D., T. D. McBride, and K. J. Mueller. 2001. "Geographic Variation in Determinants of Medicare Managed Care Enrollment." Health Services Research 36 (4): 733-50.

Rice, T., R. Snyder, G. Kominski, and N. Pourat. 2002. "Who Switches from Medigap to Medicare HMOs?" Health Services Research 37 (2): 273-90.

Riley, G., C. Tudor, Y. Chiang, and M. Ingber. 1996. "Health Status of Medicare Enrollees in HMOs and Fee-for-Service in 1994." Health Care Financing Review 17 (4): 65-76.

Swartz, K. 1999. "Medicare 'Premium Supports." Inquiry 36 (1): 5-7.

Shea, D. G., and R. P. Stewart. 1995. "Demand for Insurance by Elderly Persons: Private Purchases and Employer Provision." Health Economics 4 (4): 315-26.

United States General Accounting Office. 1997a. Medicare HMO Enrollment: Area Differences Affected by Factors Other Than Payment Rates. Report to the Honorable John F. Kerry, U.S. Senate. GAO/HEHS-97-37.

- 1997b. Medicare: Fewer and Lower Cost Beneficiaries with Chronic Conditions Enroll in HMOs. Report to the Chairman, Subcommittee on Health, Committee on Ways and Means, House of Representatives. GAO/HEHS-97-160.

Vistnes, J. P., and J. S. Banthin. 1997. "The Demand for Medicare Supplemental Insurance Benefits: The Role of Attitudes Toward Medical Care and Risk." Inquiry 34 (4): 311-24.

Weiss Ratings, Inc. 2000. "Florida and New York Residents Charged Most for Medigap Policies, Utah and Maryland Residents Charged Far Less [accessed on 
November 5, 2000].” Press release, June 12. Available at: http://www.weissratings.com/ns/default5.htm.

Welch, W. P. 1996. "Growth in HMO Share of the Medicare Market, 1989-1994." Health Affairs 15 (3): 201-14.

Wolfe, J. R., and J. H. Goddeeris. 1991. "Adverse Selection, Moral Hazard, and Wealth Effects in the Medigap Insurance Market." Journal of Health Economics 10 (4): 433-59. 